\title{
ANTECEDENTES DA INTENÇÃO DE COMPRA DE MARCAS PRÓPRIAS: UM ESTUDO NO MERCADO EMERGENTE
}

\author{
Predictors of store brand purchase intention: A study in the emerging market \\ Antecedentes de la intención de compra de marcas propias: Un estudio en el \\ mercado emergente
}

\begin{abstract}
RESUMO
Este estudo investiga preditores da intenção de compra de marcas próprias e suas inter-relações. Aprofunda-se a linha de pesquisa sobre formação da intenção de compra pela modelagem de construtos ainda não avaliados simultaneamente em estudos anteriores, a saber: imagem da loja, risco percebido, imagem da marca própria e atitude em relação à marca própria. Para testar as hipóteses oriundas da literatura sobre o tema, dados foram coletados por meio de uma survey com 1.938 clientes de supermercados no Brasil. Os resultados, obtidos por meio de modelagem de equações estruturais utilizando PLS, demonstram que há relacionamentos significativos entre (1) risco percebido e imagem da marca própria; (2) imagem da loja e imagem da marca própria; (3) imagem da marca própria e atitude; e (4) entre atitude e intenção de compra. Conclui-se que o risco percebido e a imagem da loja são fortes preditores da imagem da marca própria e da atitude, compondo um modelo robusto de predição da intenção de compra de marca própria e perfazendo contribuição a literatura.
\end{abstract}

PALAVRAS-CHAVE | Marca própria, risco percebido, imagem da loja, imagem de marca própria, intenção de compra.

\begin{abstract}
The present study investigates predictors of store brand purchase intention and the interrelations between them. It deepens the research about purchase intention formation using a modelling of constructs that have not been simultaneously examined in previous studies: store image, perceived risk, store brand image, and attitude towards the store brand. To test the hypotheses from the literature on the subject, we collected data through a survey with 1,938 supermarket customers in Brazil. Our results, found by means of structural equation modeling using PLS, demonstrate the existence of significant relationships between: (1) perceived risk and store brand image; (2) store image and store brand image; (3) store brand image and attitude; and (4) between attitude and purchase intention. We conclude that perceived risk and store image are strong predictors of store brand image and attitude, thereby forming a robust model of prediction of store brand purchase intention and providing a contribution to the literature.
\end{abstract}

KEYWORDS / Store brand, perceived risk, store image, store brand image, purchase intention.

\section{RESUMEN}

Este estudio investiga predictores de la intención de compra de marcas propias y sus interrelaciones. La línea de investigación profundiza sobre la formación de la intención de compra por el modelado de cons. tructos aún no evaluados simultáneamente en estudios anteriores, como: imagen de la tienda, riesgo percibido, imagen de la marca propia y actitud en relación a la marca propia. Para verificar las hipótesis oriundas de la literatura sobre el tema, se recolectaron datos por medio de una encuesta con 1.938 clientes de supermercados en Brasil. Los resultados, obtenidos por medio de modelado de ecuaciones estructurales utilizando PLS, demuestran que hay relaciones significativas entre (1) riesgo percibido $e$ imagen de la marca propia; (2) imagen de la tienda e imagen de la marca propia; (3) imagen de la marca propia y actitud; $y$ (4) entre actitud e intención de compra. Se concluye que el riesgo percibido y la imagen de la tienda son fuertes predictores de la imagen de la marca propia y de la actitud, lo que compone un modelo robusto de predicción de la intención de compra de marca propia y contribuye a la a literatura.

PALABRAS CLAVE I Marca propia, riesgo percibido, imagen de la tienda, imagen de marca propia, actitud, intención de compra. 


\section{INTRODUÇÃO}

O número de varejistas que adotam produtos de marcas próprias em seu mix, como estratégia para construir uma vantagem competitiva, está aumentando. As publicações e os projetos de pesquisas acadêmicas sobre o tema na perspectiva de marketing acompanham o crescimento da adoção de marcas próprias no varejo como uma tendência mundial (Hyman, Kopf, \& Lee, 2010).

Segundo a Nielsen (2016), na América Latina, o país líder em vendas de marcas próprias é a Colômbia, com $15 \%$ de market share, seguido por Chile (10\%), Argentina (9\%) e México (8\%). De agosto de 2014 a agosto de 2015, o segmento de marcas próprias nos supermercados brasileiros movimentou mais de $\mathrm{R} \$$ 3,6 bilhões, alcançando 5,1\% de participação no mercado total, que é uma participação muito pequena quando comparada, especialmente, com alguns países da Europa, que atingem $45 \%$ de participação de mercado com suas marcas próprias.

Ao serem lançadas no Brasil, na década de 1970, como produtos de preço baixo, as marcas próprias adquiriram uma imagem de baixa qualidade, influenciando de maneira desfavorável a atitude dos consumidores. Desde então, os profissionais de marketing de varejo tem enfrentado o desafio de posicionar melhor suas marcas próprias e aumentar suas vendas.

De maneira geral, os elementos que influenciam a atitude dos consumidores e a propensão para consumirem marcas próprias relacionam-se a: renda e tamanho da família, familiaridade com a marca própria, preço, embalagem, qualidade dos produtos, risco percebido e imagem da loja (Chaniotakis, Lymperopoulos, \& Soureli, 2010; Harcar, Kara, \& Kucukemiroglu, 2006; Hidalgo, Manssur, Olavarrieta, \& Farías, 2007; Huang \& Huddleston, 2009; Kremer \& Viot, 2012; Porral \& Lang, 2015; Porral \& Levy-Mangin, 2016; Sarkar, Sharma, \& Kalro, 2016).

Neste trabalho, objetiva-se investigar os antecedentes da intenção do consumidor em comprar marcas próprias em supermercados. Especificamente, procura-se compreender as relações entre imagem da loja e risco percebido com a imagem da marca própria, bem como as relações desses construtos com a atitude geral e a intenção de compra.

Apesar de a literatura sobre o tema ser vasta, sua distribuição pelo mundo é irregular. "Parece haver uma escassez de conhecimento, particularmente em mercados emergentes como a África do Sul, quanto à maneira pela qual os consumidores avaliam cognitivamente marcas próprias" (Beneke \& Carter, 2015, p. 22). Diallo (2012) ressalta que os fatores relacionados à imagem e ao risco percebido são fortes preditores na intenção de compras de marcas próprias no contexto de mercados emergentes, que são pouco investigados e requerem estudos envolvendo tais temas. Nesse sentido, o estudo desses temas no contexto brasileiro justifica-se pela baixa participação de mercado das marcas próprias em supermercados.

Além disso, há pouco consenso quanto aos fenômenos, conceituados operacionalmente sob forma de medidas psicométricas, relevantes para se entender essa avaliação cognitiva, que, por sua vez, resulta em comportamento intencional de comprar ou não marcas próprias. A literatura mostra que há considerável esforço de pesquisa em encontrar modelos explicativos da intenção de compra de marcas próprias ajustados a realidades regionais. 0 desenvolvimento científico de modelos pressupõe reducionismo, mas seus limites ampliam-se com técnicas de coleta e análise de dados.

O trabalho de Beneke e Carter (2015) apresenta o que consideram novos antecedentes para o processo de atribuição de valor percebido, um precedente direto de intenção de compra de marcas próprias.

Em linha com esse esforço de modelagem e refinamento de construtos, as principais contribuições deste estudo são (1) a análise simultânea dos construtos risco percebido, imagem da loja, atitude e imagem da marca própria como preditores de intenção de compra de marca própria, combinação ainda não estudada; (2) análise das interações entre esses preditores e (3) identificação das variáveis-chave para o aprimoramento da explicação da intenção de compra de produtos de marcas próprias.

Na sequência, o trabalho apresenta e discute o referencial teórico e desenvolvimento das hipóteses. Em seguida, são apresentados o método de pesquisa adotado, os resultados e análises e, por fim, as considerações finais.

\section{MARCAS PRÓPRIAS: UM PANORAMA}

As marcas desempenham importante papel na composição do mix de produtos do varejista, pois contribuem para o posicionamento do varejo e auxiliam os clientes em suas escolhas. Marcas próprias são marcas desenvolvidas e vendidas exclusivamente por varejistas ou atacadistas, e podem levar o nome da empresa ou outro (Parente \& Barki, 2014).

Um dos objetivos dos varejistas com a inserção das marcas próprias é aumentar a lealdade do consumidor às lojas da rede. Entretanto, Dawes e Nenycz-Thiel (2013) destacam que, para isso, deverão investir na qualidade desses produtos, que é importante para a atratividade da loja e para evitar contaminação negativa da imagem do varejista devido à má imagem da marca própria (Olbrich \& Jansen, 2014). As marcas próprias estão se consolidando no setor de alimentos, por ofertarem qualidade similar às marcas nacionais, a preços competitivos (Rubio, Oubiña, \& Villaseñor, 2014). 
No mercado brasileiro, os varejistas estão desenvolvendo diferentes programas de marcas próprias (Diallo, 2012). Há varejistas que trabalham suas estratégias com foco em preço baixo, mas há grandes redes de varejo que adotam estratégia de diferenciação para suas marcas próprias (Associação Brasileira de Supermercados [Abras], 2014). É crescente a aceitação de produtos de marcas próprias por um amplo segmento sociodemográfico de consumidores (Shuklay, Banerjee, \& Adidam, 2013). No Brasil, as marcas próprias são consumidas principalmente pelas classes A/B (Nielsen, 2015).

\section{RISCO PERCEBIDO NA COMPRA DE PRODUTOS DE MARCA PRÓPRIA}

Quando se trata de produtos de marcas próprias, o risco percebido é relevante, especialmente ao comparar as alternativas de marcas próprias com as de marcas nacionais (Dick, Jain, \& Richardson, 1995). Para Rubio et al. (2014), os consumidores percebem as marcas nacionais como mais seguras e com menor variação na qualidade do que as marcas próprias. Pereira (2001) ressalta que, de maneira geral, as marcas próprias são comercializadas com preços mais baixos em relação às marcas nacionais, o que pode comprometer a imagem da marca própria. Isso ocorre porque o risco percebido tende a ser mais baixo quando os preços são mais altos, uma vez que os consumidores assumem uma relação linear entre preço e qualidade (Olbrich \& Jansen, 2014). Assim, a inferioridade percebida nas marcas próprias é uma fonte de incerteza acerca do nível de satisfação para os consumidores desse tipo de marca, aumentando o risco associado à sua compra (Mieres, Martín, \& Gutiérrez, 2006).

Seis diferentes tipos de riscos percebidos são encontrados na literatura: risco financeiro, social, físico, psicológico, de tempo e de desempenho (Laforet, 2007; Mitra, Reiss, \& Capella, 1999; Solomon, 2011; Stone \& Gronhaug, 1993).

O risco financeiro pode ser definido como a possibilidade de perda monetária causada pela má escolha no processo de compra (Zielke \& Dobbelstein, 2007). O risco social relaciona-se à força da crença do cliente de que ele possa ser avaliado negativamente por terceiros devido à marca escolhida (Liljander, Polsa, \& Riel, 2009). O risco físico é o medo causado pela possibilidade de um produto prejudicar a saúde ou ferir fisicamente uma pessoa (Mieres et al., 2006). 0 risco psicológico pode ser descrito como a antecipação de possível decepção por parte do consumidor em selecionar um produto de má qualidade, afetando seu bemestar mental (Ueltschy, Krampf, \& Yannopoulos, 2004). 0 risco do tempo relaciona-se à possível perda de tempo associada à compra de um produto insatisfatório (Mitra et al., 1999). 0 risco de desempenho representa o medo que o consumidor tem de o produto não oferecer o desempenho prometido (Agarwal \& Teas, 2001).

Stone e Gronhaug (1993) ressaltam que o risco percebido na compra varia entre pessoas e produtos. Wu, Yeh, e Hsiao (2011) utilizaram três dimensões da escala de risco percebido (risco financeiro, risco de desempenho e risco psicológico), desenvolvida por Stone e Gronhaug (1993). Já Diallo (2012) usou apenas as dimensões risco de desempenho e risco financeiro em seu estudo. 0 autor ressalta que Liljander et al. (2009) demonstraram que essas são as dimensões mais associadas ao comportamento de compra de marcas próprias, porém, não há um consenso sobre os tipos de riscos mais relevantes no contexto de marcas próprias (Sheau-Fen, Sun-May, \& Yu-Ghee, 2012).

Para o desenvolvimento deste estudo, foram consideradas as dimensões risco de desempenho e risco financeiro, como adotado por Diallo (2012) e Liljander et al. (2009). Acrescentou-se, ainda, a dimensão risco físico, pelo fato de que, em supermercados, os produtos de marcas próprias mais adquiridos são alimentos e produtos de limpeza doméstica, percebidos como potencialmente arriscados à saúde (Derbaix, 1983; Hornibrook, McCarthy, \& Fearne, 2005; Wang, 2015). Para Golan, Roberts, e Ollinger (2004), a segurança dos produtos alimentares é difícil de ser avaliada pelos consumidores, antes ou até mesmo depois de serem consumidos, representando um obstáculo para o comportamento de compra do consumidor (Yeung, Yee, \& Morris, 2010), que tem se preocupado com resíduos de aditivos nos alimentos, hormônios nas carnes, pesticidas, conservantes etc. (Wang, 2015), os quais são prejudiciais à saúde.

Liljander et al. (2009) e Mieres et al. (2006) afirmam que o risco financeiro tem efeito negativo na intenção de compra de marcas próprias. Produtos mais complexos de serem produzidos são mais relacionados ao risco funcional, pois apresentam mais desafios para o fabricante em produzi-los (Semeijn, Riel, \& Ambrosini, 2004).

Kakkos, Trivellas, e Sdrolias (2015), Liljander et al. (2009), Mieres et al. (2006) e Sheau-Fen et al. (2012) afirmam que o risco percebido influencia o comportamento e a intenção de compra de marcas próprias. Rzem e Debabi (2012) identificaram o risco e o valor percebidos como variáveis principais que explicam a atitude em relação à marca. Baseado nas afirmações e discussões acima, têm-se as seguintes hipóteses $(H)$ :

H1: Risco percebido tem influência negativa sobre a imagem da marca própria.

H2: Risco percebido tem influência negativa sobre a intenção de compra do consumidor em relação a marcas próprias. 


\section{IMAGEM DA LOJA E MARCA PRÓPRIA}

A partir dos anos 1990, a imagem da loja tornou-se uma das principais dimensões estratégicas na competição entre varejistas (Reardon, Miler, \& Coe, 1995). A imagem da loja é definida na mente do comprador em parte pelas qualidades funcionais e em parte pela atmosfera de atributos psicológicos (Martineau, 1958). Para Bloemer e Ruyter (1998), a imagem da loja é a soma de todos os atributos percebidos pelos clientes a partir de suas experiências com a loja.

De maneira geral, a imagem da loja envolve várias dimensões, como: atmosfera, serviços da loja, qualidade de produtos, localização, sortimento, conveniência e preço/valor. 0 investimento nessas dimensões é importante na medida em que uma melhor imagem de loja pode ajudar a marca do varejista e suas marcas próprias, criando grande diferenciação no mercado (Bao, Bao, \& Sheng, 2011), pois os consumidores usam essas dimensões como elemento influenciador de seu comportamento de compra (Diallo, 2012).

Forte relacionamento entre imagem da loja e imagem da marca própria é requisito fundamental para uma diferenciação bem-sucedida no varejo (Collins-Dodd \& Lindley, 2003). A literatura reporta um relacionamento direto entre imagem da marca e imagem da loja (Porter \& Claycomb, 1997), e que associações e avaliações positivas da loja levarão a uma imagem de marca mais favorável (Wu et al., 2011). A imagem da loja e sua reputação melhoram a imagem da marca própria e sua qualidade percebida (Porral \& Lang, 2015). Silva, Merlo, e Nagano (2012) sugerem que a imagem da loja, sua limpeza e organização, maior conhecimento e familiaridade com a loja são fatores que influenciam a disposição dos consumidores para confiar na e comprar a marca própria da loja. Assim, tem-se a seguinte hipótese $(H)$ :

H3: Imagem da loja tem influência positiva sobre a imagem da marca própria.

Os varejistas precisam conscientizar-se das conexões cognitivas entre imagem da loja e marca própria, especialmente quando disponibilizam maior variedade de marcas próprias em um mesmo ambiente (Beneke \& Zimmerman, 2014). No contexto de supermercados, se o consumidor tem uma imagem positiva da loja, poderá desenvolver atitude positiva para com a marca própria daquele supermercado (Collins-Dodd \& Lindley, 2003). Para Richardson, Dick, e Jain (1996), a imagem da loja tem efeito positivo na atitude em relação aos produtos de marcas próprias, funcionando como um combustível para a atitude do consumidor em relação à marca própria do varejista, e é um importante preditor da atitude em relação a essas marcas (Semeijn et al., 2004).
Vahie e Paswan (2006) afirmam que, para influenciar positivamente a atitude dos consumidores, o varejista deve estar atento não apenas ao merchandising, mas a toda atmosfera da loja (Parente \& Barki, 2014). Martínez-Ruiz, Ruiz-Palomino, Martinez-Canas, e Blázquez-Resino (2014) identificaram que os atributos da loja que proporcionam conveniência na compra e uma atmosfera especial da loja são importantes para melhorar a lealdade atitudinal dos consumidores propensos a comprar marcas próprias. A partir das discussões dos autores, têm-se a seguinte hipótese $(H)$ :

H4: Imagem da loja tem influência positiva sobre a atitude do consumidor frente às marcas próprias.

A imagem da loja tem efeito positivo e direto na avaliação do consumidor em relação às marcas próprias (Liljander et al., 2009; Semeijn et al., 2004). Estudos sugerem que a imagem favorável da loja pode melhorar a imagem e a qualidade percebida da marca própria do varejista (Semeijn et al., 2004), reduzindo, assim, os riscos associados à sua compra pelos consumidores (Diallo, 2012; Liljander et al., 2009). Esses autores identificaram que a imagem da loja tem influência direta e negativa no risco percebido em relação à marca própria, ou seja, a imagem da loja tem efeito redutor do risco percebido.

A imagem da loja é composta por fatores extrínsecos que, segundo Ailawadi e Keller (2004), amenizam o risco percebido, pela melhoria do posicionamento das marcas próprias (DelgadoBallester, Hernandez-Espallardo, \& Rodriguez-Orejuela, 2014). Mitchell (1998) complementa que a percepção da qualidade da loja leva à redução do risco percebido. Nesse sentido, DelgadoBallester et al. (2014) sugerem ao varejista o investimento na criação e na manutenção de uma imagem positiva da loja. Além disso, a imagem da loja tem efeito positivo sobre a intenção de compra de marca própria, sendo considerada um antecedente da intenção (Beneke, Brito, \& Garvey, 2015; Liljander et al., 2009; Porral \& Levy-Mangin, 2016; Wu et al., 2011). Com base nas discussões dos autores, tem-se a seguinte hipótese $(H)$ :

$\mathrm{H}_{5}$ : Imagem da loja tem influência negativa sobre o risco percebido em relação às marcas próprias.

\section{IMAGEM DA MARCA PRÓPRIA}

A imagem de uma marca é a soma total das associações realizadas na memória do consumidor decorrentes de suas percepções sobre a marca (Keller, 1993) e serve como garantia do produto (Dodds, Monroe, \& Grewal, 1991). A imagem da marca própria é formada pelas dimensões afetiva e de qualidade da marca (Vahie \& Paswan, 2006). Esses autores identificaram que os 
impactos da imagem da loja sobre a dimensão afetiva da marca própria incluem a conveniência, a qualidade e a percepção de preço versus valor. Essas dimensões influenciam positivamente a atitude do consumidor em torno das marcas próprias.

Há certo consenso na literatura de que uma imagem de marca favorável tem impacto positivo sobre o comportamento do consumidor para com a marca, proporcionando ao varejista aumento do número de compradores leais à loja, maior possibilidade de praticar preços superiores e um boca a boca mais positivo (Martenson, 2007). Para Laroche, Kim, e Zhou (1996), os consumidores têm uma atitude positiva e maior intenção de compras para com as marcas que têm melhor imagem. Os consumidores comprarão marcas próprias se as perceberem como produtos de qualidade e se tiverem imagem positiva da marca (Sethuraman \& Gielens, 2014). Hidalgo et al. (2007) sugerem que um plano de comunicação integrada eficaz fortalece a imagem da marca própria e melhora a atitude do consumidor diante desses produtos.

Os consumidores utilizam os atributos extrínsecos para avaliar a qualidade e reduzir o risco percebido nas marcas próprias (Wu et al., 2011). Ailawadi e Keller (2004) afirmam que os varejistas podem criar sua imagem de marca por meio de associações únicas para a qualidade de seus serviços. Para Hoch e Banerj (1993) e Richardson, Dick, e Jain (1994), se o padrão de qualidade das marcas próprias é similar ao das marcas nacionais, cria-se uma imagem favorável das marcas próprias, e, consequentemente, melhor qualidade percebida influencia positivamente a atitude do consumidor diante dessas marcas (Harcar et al., 2006). Baseado nas discussões dos autores, têm-se as seguintes hipóteses:

H6: Imagem da marca própria tem efeito positivo sobre a atitude do consumidor em relação às marcas próprias.

H7: Imagem da marca própria tem efeito positivo sobre a intenção de compra de marcas próprias.

\section{ATITUDE EM RELAÇÃO À MARCA PRÓPRIA}

Keller (1993) define atitude como uma avaliação geral da marca por parte dos consumidores, e essa atitude forma a base para as decisões e comportamentos em torno da marca (Grace \& O'Cass, 2004). Quanto ao processo de formação da atitude, Fishbein e Ajzen (1975) destacam o conceito de crença que, de maneira geral, perfaz o elo entre os atributos dos objetos e a própria atitude. Os indivíduos apresentam uma série de crenças em relação a um determinado objeto, que, em suma, são os determinantes da atitude dos indivíduos e, normalmente, antecedem a intenção comportamental, e, por conseguinte, o próprio comportamento desses indivíduos em relação a um determinado produto (Hoppe, Barcellos, Vieira, \& Matos, 2012).

Semeijn et al. (2004) destacam a composição do mix de produtos, suas exposições e o nível de serviço como elementos utilizados na construção de crenças sobre o varejista e que, consequentemente, determinam a atitude do consumidor em relação às suas marcas. Chaniotakis et al. (2010) identificam a relação entre atitude e intenção de compra, que, segundo Wu et al. (2011), representa a possibilidade de que os consumidores estarão dispostos a comprar determinado produto no futuro.

Para Chaniotakis et al. (2010), a intenção de compra é diretamente afetada pela atitude dos consumidores em relação à marca própria; quanto mais favorável, mais forte deverá ser a intenção individual de cumpri-la (Armitage \& Conner, 2001). Com base nas discussões acima, propõe-se a seguinte hipótese:

H8: Atitude tem influência positiva sobre a intenção de compra de marcas próprias.

\section{Modelo conceitual}

A Figura 1 apresenta uma visão sumária das relações entre os construtos estabelecidas como hipóteses neste estudo.

\section{Figura 1. Modelo de relações dos construtos e hipóteses}

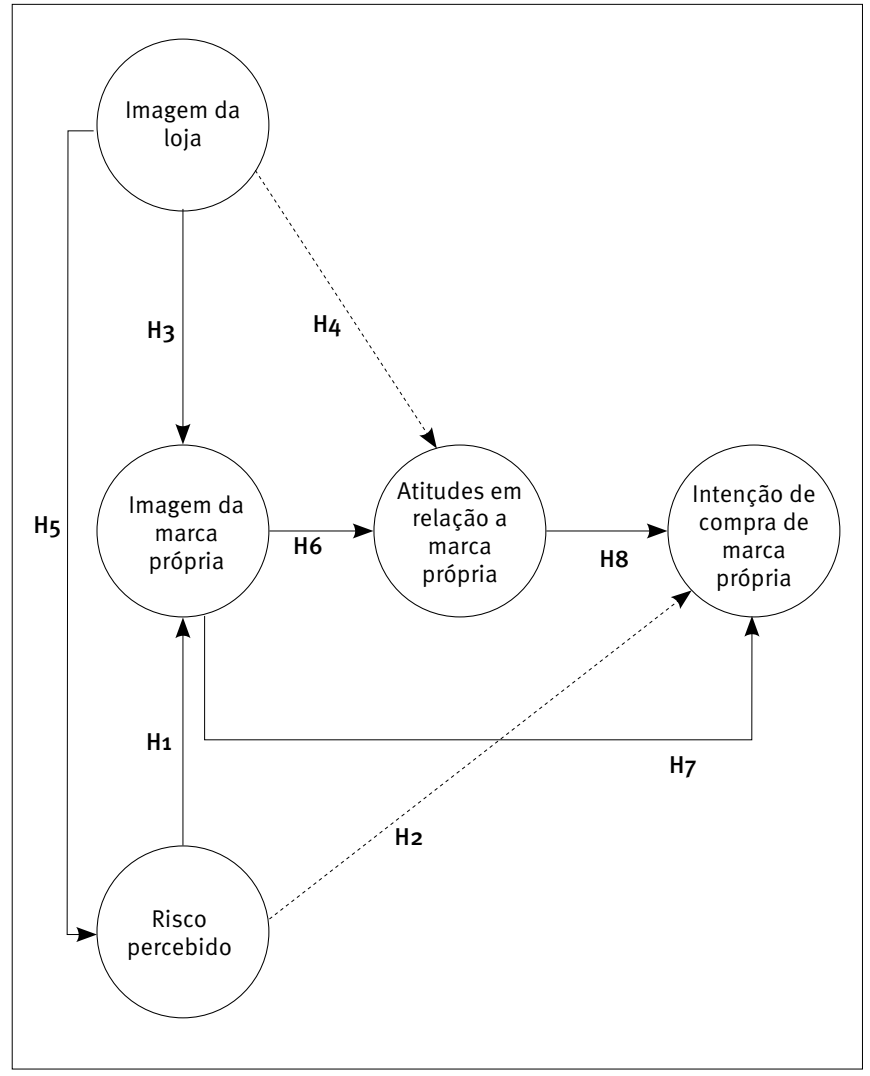


O modelo proposto para o desenvolvimento do estudo considera a imagem da loja e o risco percebido construtos que exercem relação direta com a imagem da marca própria, que, por sua vez, tem efeito direto na atitude e influencia a intenção de compra de marca própria. 0 modelo também preconiza que a imagem da marca própria tem ligação com a intenção de compra e que a imagem da loja pode reduzir o risco percebido. Além disso, pressupõe que a imagem da loja tem efeito direto na atitude e que o risco percebido tem efeito direto na intenção de compra de marca própria.

\section{METODOLOGIA}

A pesquisa de campo foi realizada por meio de formulários estruturados, enviados por correio eletrônico para um banco de e-mails selecionado de consumidores brasileiros de supermercados.

A técnica amostral adotada para o desenvolvimento da survey foi não probabilística por conveniência, uma vez que o propósito da pesquisa foi testar hipóteses do modelo, e não fazer inferências para uma população de interesse. 0 pré-teste foi desenvolvido com 50 consumidores para detectar deficiências em termos utilizados no enunciado das questões e dificuldades no preenchimento das respostas que pudessem ocasionar falhas no processo de coleta. Além disso, o pré-teste foi utilizado para validar a tradução das escalas tanto de forma qualitativa quanto quantitativa, por testes preliminares de confiabilidade (alfa de Cronbach).

O formulário de coleta de dados foi desenvolvido no software Lime Survey, um programa livre utilizado e hospedado na universidade que possibilita coletar dados por autopreenchimento dos respondentes. O convite com o link para o formulário foi enviado para 62.340 e-mails válidos e teve taxa de retorno de 3,25\%, ou seja, retornaram 2.045 questionários respondidos. Foram excluídos 107 questionários preenchidos de maneira inadequada, ficando uma amostra de 1.938 consumidores.

Para compreensão clara acerca do significado de marcas próprias e para que fosse obtida maior eficiência nas respostas, foram apresentadas ilustrações gerais de produtos e uma breve explicação sobre o conceito de marcas próprias. A coleta de dados ocorreu entre $1^{\circ}$ de junho e $1^{\circ}$ de julho de 2014.

\section{Medidas}

No início do questionário, perguntou-se o nome da marca própria mais adquirida pelo respondente. 0 objetivo foi direcionar as questões do modelo aos objetos focais específicos de avaliação: a marca própria e o supermercado (loja). A frequência com que marcas e lojas foram citadas é irrelevante para os objetivos deste estudo.

Para avaliação dos construtos componentes do modelo, utilizou-se uma escala de concordância de 7 pontos, onde 7 significava "concordo totalmente" e 1, "discordo totalmente". Todas as escalas utilizadas já haviam sido validadas na literatura, e as dimensões com suas variáveis aplicadas no questionário estão apresentadas no Quadro 1.

Para o tratamento de dados, foi utilizado, inicialmente, o software SPSS (Statistical Package for Social Sciences), base 17.0. Foram utilizadas técnicas estatísticas descritivas para descrever o perfil da amostra e, em seguida, desenvolveu-se a análise de confiabilidade das escalas utilizadas. Por fim, aplicou-se a análise fatorial exploratória a fim de verificar a independência (ortogonalidade) entre os construtos estudados.

Uma vez considerados aceitáveis, os dados foram transferidos para o SmartPLS, versão profissional 3.0, que foi usado para estimação do modelo de mensuração e das relações entre os construtos.

Segundo Bido, Silva, Souza, e Godoy (2010), a modelagem em equações estruturais (MEE), ferramenta que permite a avaliação de relações entre construtos não mensuráveis diretamente (variáveis latentes), “abrange basicamente dois tipos de métodos de estimação: o primeiro é conhecido como modelagem de equações estruturais baseado em covariâncias (MEEBC) ou, simplesmente, modelos LISREL; o segundo é conhecido como Mínimos Quadrados Parciais (Partial Least Squares) (MEEPLS), que realiza a avaliação do MEE por partes. Mais recentemente, esse último método tem sido denominado PLS-PM (Partial Least Squares - Path Modeling)” (p. 246).

Os autores justificam o uso do método com o mesmo argumento que se aplica ao presente trabalho: “Um dos motivos para se usar PLS-PM em detrimento de outros métodos é a possibilidade de se modelarem variáveis latentes com indicadores formativos, pois tradicionalmente se usavam, prioritariamente, indicadores reflexivos, como definido pela psicometria. Esclarecendo mais, os indicadores são formativos quando explicam o constructo, e não é esperado que haja correlação entre eles, enquanto os reflexivos são os indicadores explicados pelos constructos (indicadores-efeito), tal como nas escalas de atitude" (Bido et al., 2010, p. 248). 


\section{Quadro 1. Composição dos construtos utilizados na modelagem comportamental}

\begin{tabular}{|c|c|}
\hline $\begin{array}{l}\text { Construto/ } \\
\text { autores }\end{array}$ & Dimensões e variáveis \\
\hline $\begin{array}{l}\text { Imagem da loja } \\
\text { Chowdhury, } \\
\text { Reardon, \& } \\
\text { Srivastava (1998) } \\
\text { e Semeijn et al. } \\
\text { (2004) }\end{array}$ & 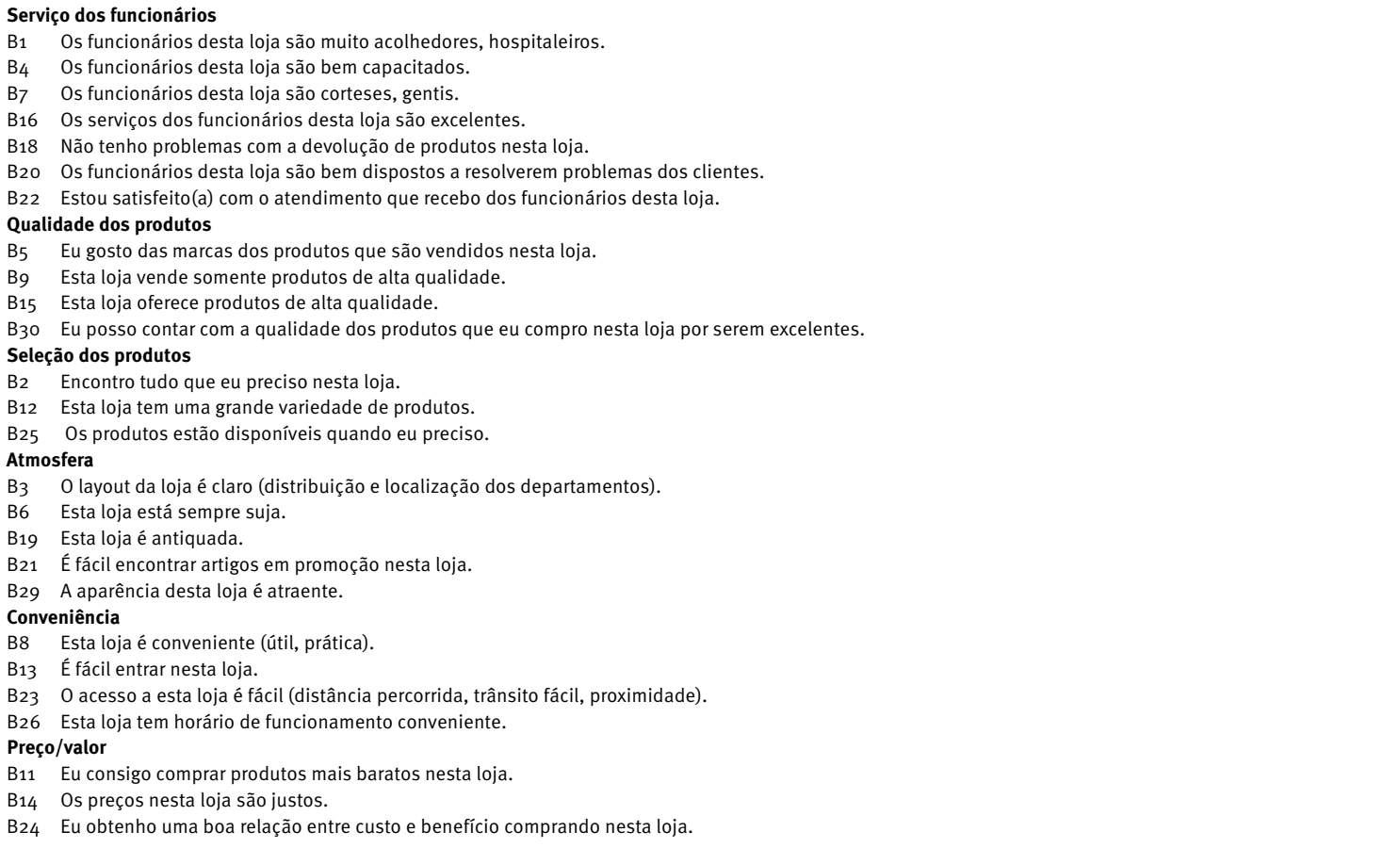 \\
\hline $\begin{array}{l}\text { Risco percebido } \\
\text { Stone \& Gronhaug } \\
\text { (1993) }\end{array}$ & $\begin{array}{l}\text { Risco financeiro } \\
\text { C1 } \\
\text { C6 } 6 \text { Se eu comprar produtos de marca própria, vou gastar mal o meu dinheiro. } \\
\text { C9 } \text { Se eu comprar produtos de marca própria, ficarei pensando se o investimento financeiro foi bem feito. } \\
\text { Risco funcional ou de desempenho } \\
\text { C3 Ao considerar a compra de marca própria para o uso, preocupa-me se o produto realmente vai funcionar tão bem quanto eu espero. } \\
\text { C8 A ideia de comprar produtos de marca própria causa-me preocupação pelo quanto este produto pode ser seguro e confiável. } \\
\text { C10 Se eu fosse comprar produtos de marca própria para o uso, eu ficaria preocupado(a) quanto ao produto não oferecer o nível de benefícios que eu espero. } \\
\text { Risco físico } \\
\text { C2 Devido à possível falta de segurança de alguns produtos de marca própria, ao considerar este tipo de produto para uso doméstico, preocupo-me com os riscos } \\
\text { físicos potenciais associados a ele. } \\
\text { C4 A compra de marca própria para uso doméstico preocupa-me no que diz respeito a o produto causar efeitos colaterais físicos desconfortáveis. } \\
\text { C11 Uma preocupação que tenho a respeito da compra de marca própria para o uso doméstico é que provavelmente fará mal, devido ao uso excessivo do produto. }\end{array}$ \\
\hline $\begin{array}{l}\text { Imagem da marca } \\
\text { própria } \\
\text { Vahie \& Paswan } \\
(2006)\end{array}$ & $\begin{array}{l}\text { Afetiva } \\
\text { D2 Estou satisfeito(a) com a maioria dos produtos de marca própria que eu compro nesta loja. } \\
\text { D4 Eu gosto muito da marca própria desta loja. } \\
\text { Qualidade } \\
\text { D1 Muitos produtos de marca própria que eu compro nesta loja estão com algum tipo de defeito. } \\
\text { D3 Esta loja não se importa muito com a qualidade de seus produtos de marca própria. } \\
\text { D5 }\end{array}$ \\
\hline $\begin{array}{l}\text { Atitude } \\
\text { Burton, } \\
\text { Lichtenstein, } \\
\text { Netemeyer, \& } \\
\text { Garretson (1998) }\end{array}$ & $\begin{array}{l}\text { E1 Quando eu compro marcas próprias, eu sempre sinto que estou fazendo um bom negócio. } \\
\text { E2 Eu gosto muito quando marcas próprias estão disponíveis nas categorias de produtos que compro. } \\
\text { E3 Em geral, as marcas próprias são produtos de baixa qualidade. } \\
\text { E4 Para a maioria das categorias de produtos, a melhor opção de compra é geralmente a marca própria. } \\
\text { E5 Considerando a relação entre custo e benefício, eu prefiro marcas próprias às demais marcas (marcas do fabricante). } \\
\text { E6 Comprar marca própria me faz sentir bem. }\end{array}$ \\
\hline $\begin{array}{l}\text { Intenção de compra } \\
\text { Diallo (2012) e } \\
\text { Knight \& Kim (2007) }\end{array}$ & $\begin{array}{ll}\text { F1 } & \text { Tenho a intenção de comprar produtos de marca própria desta loja com frequência. } \\
\text { F2 } & \text { Eu consideraria a compra de uma marca própria. } \\
\text { F3 }_{3} & \text { Existe uma forte possibilidade de eu comprar produtos de marca própria. } \\
\text { F4 } & \text { Eu compraria produtos de marca própria na próxima vez que eu for ao supermercado. } \\
\text { F5 } & \text { A probabilidade de considerar a compra de produtos de marca própria é alta. } \\
\text { F6 } & \text { Eu pretendo comprar produtos de marca própria desta loja com mais frequência. }\end{array}$ \\
\hline
\end{tabular}




\section{RESULTADOS E ANÁLISES}

A seguir, apresentam-se os resultados e análises da pesquisa de campo em relação a cada um dos elementos pesquisados.

\section{Caracterização da amostra}

A população amostrada são pessoas que têm relação com a universidade, como ex-alunos, professores, consultores etc. 0 convite foi para toda a base de contatos existente, e a amostra foi de 1.938 , descrita a seguir.

Do total de respondentes, 925 pertenciam ao sexo feminino ( $47,7 \%$ ) e 1.013 , ao sexo masculino (52,1\%), permitindo uma coleta equilibrada de opiniões entre os sexos. Em relação à faixa etária, a maior parte da amostra encontrava-se entre 31 e 40 anos (35\%), seguida das faixas entre 41 e 50 anos (22,9\%) e entre 21 e 30 anos (20,4\%). Os $21,7 \%$ restantes da amostra estão distribuídos nas demais faixas etárias, sendo 15,9\% entre 51 e 60 anos, 5,3\% acima de 60 anos e apenas 0,5\% na faixa etária de até 20 anos.

Com respeito ao nível de escolaridade, a amostra foi composta por $75,7 \%$ de pós-graduados, seguida de $20,3 \%$ de pessoas com nível superior completo, 3\% com superior incompleto e apenas $1 \%$ com ensino médio incompleto ou completo. Em relação à renda, a maior parte da amostra era de pessoas com renda superior a $R \$ 7.001,00$ (55,8\%), entre $R \$ 3.501,00$ e $R \$ 7.000,00$ (29,2\%), entre $R \$ 1.501,00$ e $R \$$ $3.500,00(12,2 \%)$, e apenas $2,8 \%$ da amostra com renda até $\mathrm{R} \$ 1.500$,00. Observa-se que grande parte da amostra consumidora de produtos de marcas próprias está classificada como pessoas mais maduras, acima de 30 anos, pertencentes a classes socioeconômicas mais altas, o que está de acordo com o apontado pela Nielsen (2015).

A amostra teve origem nos 26 estados do Brasil e no Distrito Federal, residindo a maioria no estado de São Paulo $(60,6 \%)$, seguido de Rio de Janeiro (7\%), Minas Gerais (4,6\%), Paraná e Rio Grande do Sul, com 3,8\% e 3,6\%, respectivamente, Bahia (2,4\%), e dos demais estados ( $18 \%$ da amostra).

\section{Confiabilidade e ortogonalidade dos construtos}

A Tabela 1 apresenta as cargas fatoriais de cada variável dos construtos. Observa-se que as cargas fatoriais das variáveis dos construtos estão dentro do valor recomendado na literatura; segundo Afthanorhan (2013), cargas maiores que 0,5 devem ser mantidas no modelo e menores devem ser retiradas, pois comprometem a confiabilidade dos construtos.
Tabela 1. Outer loadings (cargas fatoriais das variáveis dos construtos)

\begin{tabular}{|c|c|c|c|c|c|}
\hline Variáveis & Atitude & $\begin{array}{l}\text { Imagem } \\
\text { da loja }\end{array}$ & $\begin{array}{l}\text { Imagem } \\
\text { da marca } \\
\text { própria }\end{array}$ & $\begin{array}{c}\text { Intenção } \\
\text { de compra }\end{array}$ & $\begin{array}{c}\text { Risco } \\
\text { percebido }\end{array}$ \\
\hline Atmosfera & & 0,809 & & & \\
\hline Conveniência & & 0,772 & & & \\
\hline Preco_vr & & 0,512 & & & \\
\hline Qual_Prod & & 0,893 & & & \\
\hline Serv_Func & & 0,764 & & & \\
\hline Sort_Prod & & 0,848 & & & \\
\hline D2_IMP_A_1 & & & 0,828 & & \\
\hline D3_IMP_Q2 & & & 0,604 & & \\
\hline D4_IMP_A_2 & & & 0,854 & & \\
\hline D5_IMP_Q_3 & & & 0,613 & & \\
\hline E1_ATT_1 & 0,834 & & & & \\
\hline E2_ATT_2 & 0,836 & & & & \\
\hline E4_ATT_4 & 0,697 & & & & \\
\hline E5_ATT_5 & 0,775 & & & & \\
\hline E6_ATT_6 & 0,805 & & & & \\
\hline F1_INTC_1 & & & & 0,856 & \\
\hline F2_INTC_2 & & & & 0,812 & \\
\hline F3_INTC_3 & & & & 0,937 & \\
\hline F4_INTC_4 & & & & 0,931 & \\
\hline F5_INTC_5 & & & & 0,933 & \\
\hline F6_INTC_6 & & & & 0,880 & \\
\hline Ris_Des & & & & & 0,933 \\
\hline Ris_Fin & & & & & 0,929 \\
\hline Ris_Fisico & & & & & 0,878 \\
\hline
\end{tabular}

Para assegurar a consistência interna de cada construto, foi analisado o alfa de Cronbach, que, conforme apresentado na Tabela 2, excedeu o valor crítico de o,7, o que assegura que os construtos foram medidos de modo consistente (Fornell \& Larcker, 1981; Henseler, Ringle, \& Sinkovics, 2009). 
Tabela 2. Tabela 2. Valor do alfa de Cronbach de cada construto do modelo de pesquisa

\begin{tabular}{l|c}
\hline Variáveis & Alfa de Cronbach \\
\hline Atitude & 0,852 \\
\hline Imagem da loja & 0,861 \\
\hline Imagem da marca própria & 0,719 \\
\hline Intenção de compra & 0,949 \\
\hline Risco percebido & 0,900 \\
\hline
\end{tabular}

\section{Teste do modelo}

A modelagem de equações estruturais, usando a análise PLS, foi conduzida para testar o modelo conceitual. A seguir, as medidas do modelo são avaliadas.

\section{Validade convergente e validade discriminante}

Observa-se, na Tabela 3, que todos os critérios sugeridos para essa análise atendem os valores recomendados por Fornell e Larcker (1981) e por Henseler et al. (2009). O alfa de Cronbach, apresentado anteriormente, é superior a 0,7; a Average Variance Extracted (AVE) é superior a 0,5 em todos os construtos e a confiabilidade composta também é superior a o,7 em todos os construtos que compõem o modelo, concluindo que os itens que deveriam estar relacionados, teoricamente, estão, de fato, inter-relacionados.

Tabela 3. Indicadores da validade convergente do modelo

\begin{tabular}{l|c|c}
\hline Variáveis & AVE & $\begin{array}{l}\text { Composite } \\
\text { reliability }\end{array}$ \\
\hline Atitude & 0.626 & 0.893 \\
\hline Imagem da loja & 0.602 & 0.899 \\
\hline Imagem da marca própria & 0.539 & 0.820 \\
\hline Intenção de compra & 0.797 & 0.959 \\
\hline Risco percebido & 0.834 & 0.938 \\
\hline
\end{tabular}

O valor da validade discriminante é obtido a partir da raiz quadrada do valor da AVE. Assim, os valores na diagonal (em negrito) são a raiz quadrada da AVE, enquanto os outros valores representam a correlação entre os respectivos construtos. Os valores da validade discriminantes estão apresentados na Tabela 4.
Tabela 4. Validade discriminante

\begin{tabular}{l|c|c|c|c|c}
\hline Variáveis & Atitude & $\begin{array}{c}\text { Imagem } \\
\text { da loja }\end{array}$ & $\begin{array}{c}\text { Imagem } \\
\text { da marca } \\
\text { própria }\end{array}$ & $\begin{array}{c}\text { Intenção } \\
\text { de compra }\end{array}$ & $\begin{array}{c}\text { Risco } \\
\text { percebido }\end{array}$ \\
\hline Atitude & 0,791 & & & & \\
\hline $\begin{array}{l}\text { Imagem da } \\
\text { loja }\end{array}$ & 0,386 & 0,776 & & & \\
\hline $\begin{array}{l}\text { Imagem } \\
\text { da marca } \\
\text { própria }\end{array}$ & 0,537 & 0,537 & 0,734 & & \\
\hline $\begin{array}{l}\text { Intenção } \\
\text { de compra }\end{array}$ & 0,722 & 0,424 & 0,619 & 0,893 & \\
\hline $\begin{array}{l}\text { Risco } \\
\text { percebido }\end{array}$ & $-0,325$ & $-0,229$ & $-0,478$ & $-0,428$ & 0,913 \\
\hline
\end{tabular}

Observa-se que a validade discriminante, nesse caso, é admitida pelo fato de os números da diagonal (em negrito) serem mais altos do que os valores em suas linhas e colunas.

\section{Modelo estrutural - Validade nomológica e coeficientes $\beta$ (path coefficients)}

A validade nomológica refere-se ao grau com que um construto se comporta como preditor dentro de um sistema de construtos relacionados. Para essa análise, observa-se se todas as relações previstas no modelo são significativas, utilizando o bootstrapping para verificar se o $t$ de Student é superior a 1,96 (valor crítico para nível de significância de 0,05). 0 uso da reamostragem (bootstrapping) é o procedimento utilizado para capturar a significância de cada relação.

A Tabela 5 apresenta o $t$ value referente a todos os relacionamentos entre os construtos. Observa-se que todos os valores são superiores a 1,96, portanto todas as cargas são significantes, representando que há correlações entre as variáveis originais e as variáveis latentes.

Tabela 5. T value dos construtos do modelo do estudo

\begin{tabular}{l|l|l|c|c|c}
\hline Variáveis & Atitude & $\begin{array}{c}\text { Imagem } \\
\text { da loja }\end{array}$ & $\begin{array}{c}\text { Imagem } \\
\text { da marca } \\
\text { própria }\end{array}$ & $\begin{array}{c}\text { Intenção } \\
\text { de compra }\end{array}$ & $\begin{array}{c}\text { Risco } \\
\text { percebido }\end{array}$ \\
\hline Atitude & & & & 28,926 & \\
\hline $\begin{array}{l}\text { Imagem da } \\
\text { loja }\end{array}$ & 5,236 & & 24,020 & & 9,883 \\
\hline $\begin{array}{l}\text { Imagem } \\
\text { da marca } \\
\text { própria }\end{array}$ & 18,585 & & & 12,410 & \\
\hline $\begin{array}{l}\text { Intenção } \\
\text { de compra }\end{array}$ & & & & & \\
\hline $\begin{array}{l}\text { Risco } \\
\text { percebido }\end{array}$ & & & 19,253 & 6,659 & \\
\hline
\end{tabular}




\section{Validade preditiva $\left(\mathrm{Q}^{2}\right)$ e tamanho do efeito $\left(\mathrm{f}^{2}\right)$}

$O$ indicador de Stone-Geisser $\left(\mathrm{Q}^{2}\right)$ avalia a qualidade da predição do modelo. Como critério de avaliação, devem ser obtidos valores maiores que zero (Hair, Hult, Ringle, \& Sarstedt, 2014). 0 indicador de Cohen ( $\left.f^{2}\right)$ avalia quanto cada constructo é “útil” para 0 ajuste do modelo. Valores de 0,02, 0,15 e 0,35 são considerados pequenos, médios e grandes, respectivamente (Hair et al., 2014). A Tabela 6 demonstra que, por meio dos valores de $Q^{2}$ e de $f^{2}$, o modelo tem qualidade de predição e todos os constructos são importantes para o ajuste geral do modelo, tendo efeito moderado apenas imagem da marca própria.
Tabela 6. Valores dos indicadores da validade preditiva $\left(Q^{2}\right)$ e do tamanho do efeito $\left(f^{2}\right)$

\begin{tabular}{l|l|l}
\hline Variáveis & CV RED $\left(Q^{2}\right)$ & CV COM $\left(f^{2}\right)$ \\
\hline Atitude & 0,181 & 0,435 \\
\hline $\begin{array}{l}\text { Imagem da loja } \\
\begin{array}{l}\text { Imagem da } \\
\text { marca própria }\end{array}\end{array}$ & 0,228 & 0,450 \\
\hline $\begin{array}{l}\text { Intenção de } \\
\text { compra }\end{array}$ & 0,478 & 0,712 \\
\hline $\begin{array}{l}\text { Risco percebido } \\
\text { Valores } \\
\text { referenciais }\end{array}$ & 0,043 & 0,641 \\
\hline
\end{tabular}

A Figura 2 mostra os coeficientes $\beta$ de cada relacionamento hipotetizado no modelo. Os coeficientes $\beta$ determinam a força e a natureza direcional das relações entre os construtos.

Figura 2. Modelo estrutural - Coeficientes $\beta$ (entre construtos) e outer loadings das variáveis originais

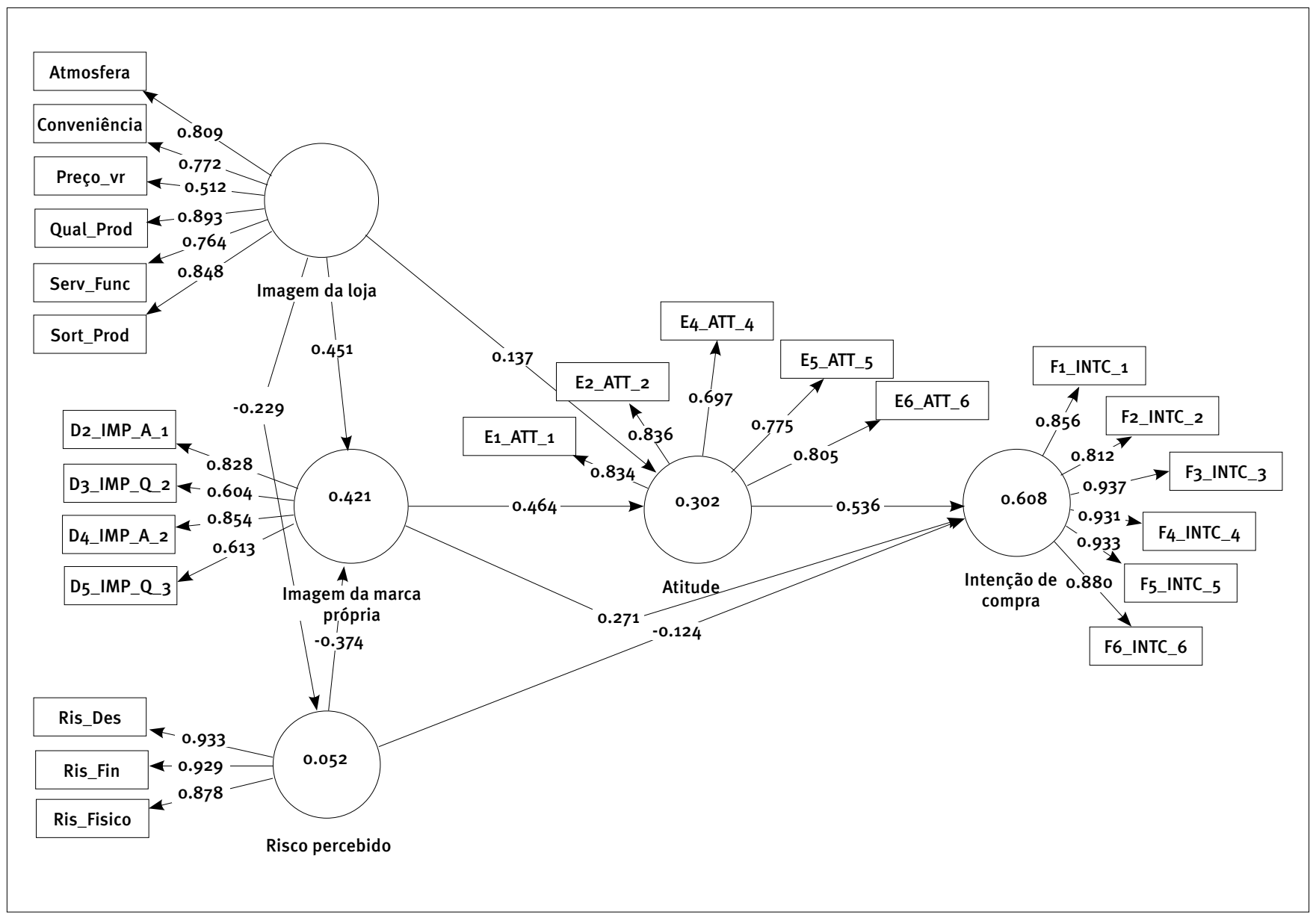

Pode-se observar que o coeficiente $\beta$ entre atitude e intenção de compra é de 0,536, o que indica um forte e positivo relacionamento entre esses dois construtos (Anderson \& Gerbing, 1988). Um forte e positivo relacionamento existe também entre a imagem da loja e imagem da marca própria $(0,451)$, entretanto uma relação fraca e positiva $(0,137)$ ocorre entre imagem da loja e atitude. Um relacionamento moderado e negativo $(-0,229)$ conecta a imagem da loja ao risco percebido. 
Há uma relação forte e positiva $(0,464)$ entre a imagem da marca própria e a atitude; e, entre os construtos imagem da marca própria e intenção de compra, o relacionamento é positivo $(0,271)$, porém moderado. A conexão entre risco percebido e imagem da marca própria é forte e negativa $(-0,374)$; já a relação entre o risco percebido e a intenção de compra é fraca e negativa $(-0,124)$.

0 valor de $\mathrm{R}^{2}$ de 0,608 para intenção de compra indica que aproximadamente $61 \%$ da variância do construto é explicada pelos construtos antecedentes identificados no modelo, enquanto o $\mathrm{R}^{2}$ de 0,302 na atitude indica que 30\% da atitude é explicada pela imagem da loja, imagem da marca própria e risco percebido. Já em relação à imagem da marca própria, o valor de $\mathrm{R}^{2}$ de 0,421 indica que $42 \%$ da variância da imagem da marca própria é explicada pela imagem da loja e pelo risco percebido. Não há um valor considerado mínimo para o $R^{2}$, apenas deve ser fruto de uma regressão significativa a $p<5 \%$. Cohen (1988) argumenta que, para a área de ciências sociais, $R^{2}=0,02$ são fracos, $R^{2}=0,13$ possuem efeito médio e $R^{2}$ superiores a 0,26 podem ser considerados expressivos.

\section{Avaliação das hipóteses e discussão dos resultados}

Observa-se, pela Figura 2, que todas as hipóteses propostas no modelo estrutural foram aceitas com significância $p<0,05$.

Este estudo identificou um relacionamento forte, significativo e negativo entre risco percebido e imagem da marca própria. Dessa forma, melhorar a qualidade dos produtos de marcas próprias, diminuir a variação da qualidade dentro das categorias e criar uma boa relação entre custo e benefício, conforme sugerido por Semeijn et al. (2004) e Zielke e Dobbelstein (2007), são ações que reduzem o risco percebido. Entre as dimensões do risco, destacam-se a dimensão risco de desempenho e risco financeiro como as que apresentaram maior efeito no construto risco percebido.

Há relacionamento negativo e significante entre risco percebido e a intenção de compra, o que corrobora os resultados encontrados por Liljander et al. (2009) e Mieres et al. (2006), que, em seus estudos, descobriram que o risco percebido influencia a intenção de compra de marcas próprias. Conclui-se, então, que o risco percebido influencia negativamente a intenção de compra de produtos de marcas próprias.

Identificou-se, também, que há relacionamento positivo, significante e forte entre imagem da loja e imagem da marca própria. Esse resultado corrobora os estudos de Collins-Dodd e Lindley (2003), que encontraram forte relacionamento entre a imagem da loja e a imagem da marca própria, e um relacionamento direto entre esses dois construtos, conforme identificado por
Porter e Claycomb (1997). Conclui-se, então, que a imagem da loja tem influência positiva na imagem da marca própria, o que significa que, ao modificar, de maneira satisfatória, os elementos ou dimensões que compõem a imagem da loja, poderá ocorrer melhoria da imagem da marca própria.

Relacionamento positivo e significante foi identificado entre os construtos imagem da loja e atitude, conforme descoberto por Dolbec e Chebat (2013), Richardson et al. (1996), Semeijn et al. (2004) e Vahie e Paswan (2006). Entretanto, neste estudo, apesar de esse relacionamento ter sido positivo e significante, foi fraco, exercendo pouca influência na formação da atitude.

Entre os construtos imagem da loja e risco percebido, foi identificado relacionamento moderado, negativo e significante, 0 que demonstra que a imagem da loja pode reduzir o risco percebido nas marcas próprias, conforme identificado por Liljander et al. (2009). No modelo testado, as dimensões qualidade do produto, sortimento de produtos e atmosfera foram as que obtiveram maiores cargas, ou seja, são as que mais influenciam a imagem da loja. Essas descobertas remetem ao fato de que, se essas dimensões forem modificadas de maneira positiva, poderão contribuir para a redução do risco percebido nas marcas próprias.

Um relacionamento positivo, forte e significante foi encontrado entre os construtos imagem da marca própria e atitude. Esse resultado está de acordo com as descobertas de Laroche et al. (1996), concluindo, então, que a imagem da marca própria exerce influência positiva na atitude do consumidor ante essas marcas. Das dimensões que compõem o construto imagem da marca própria, a dimensão afetiva exerce maior influência nesse construto, o que corrobora os resultados identificados por Vahie e Paswan (2006).

Relacionamento moderado, positivo e significante foi encontrado entre os construtos imagem da marca própria e intenção de compra, o que está de acordo com Wu et al. (2011), que identificaram que a imagem da marca própria também influencia de maneira positiva a intenção de compra, concluindo que marcas com melhor imagem desenvolverão maior intenção de compra.

Entre os construtos atitude e intenção de compra, os resultados obtidos demonstram que há relacionamento forte, positivo e significante entre esses construtos, o que corrobora os estudos de Armitage e Conner (2001) e Chaniotakis et al. (2010), podendo inferir que quanto mais favorável for a atitude do consumidor ante a marca própria, melhor será sua intenção de compra.

\section{CONSIDERAÇÕES FINAIS}

Os construtos imagem da loja, imagem da marca própria, risco percebido e atitude, analisados simultaneamente, considerados 
no modelo como antecedentes da intenção de compra, explicaram aproximadamente $61 \%$ da intenção de compra de marcas próprias. Os relacionamentos encontrados no modelo, com coeficientes $\beta$ variando entre -0,124 e 0,536, demonstram a robustez da modelagem comportamental proposta para explicar a intenção de compra de marcas próprias, ampliando a compreensão científica do fenômeno.

- De modo a finalizar a contribuição teórica do estudo, faz-se necessário um olhar sobre as dimensões que compõem cada construto, de maneira a identificar as variáveischave para o aprimoramento do entendimento de como a intenção de compra de produtos de marca própria é formada na mente dos consumidores.

- No construto imagem da loja, a qualidade do produto, o sortimento e a atmosfera são as variáveis que exercem maior peso na sua formação. Dessa forma, conclui-se que a melhoria da qualidade das marcas próprias, do planejamento do sortimento e da variedade de produtos a ser ofertado e dos aspectos da atmosfera (iluminação, layout, cores, comunicação visual, músicas) gera reflexo positivo na imagem da loja.

- No construto risco percebido, o risco de desempenho e o risco financeiro são os que exercem maior peso nesse construto. Nesse sentido, conclui-se que experiências agradáveis com marcas próprias, investimentos nos atributos intrínsecos e extrínsecos que cumpram o desempenho prometido, e uma relação mais justa entre preço e qualidade contribuem para a redução do risco percebido.

- No construto intenção de compra, as variáveis que exercem maior efeito são aquelas que denotam a intenção de compra de produtos de marca própria, mas não expressam a intenção de compra de marcas próprias com frequência. Conclui-se que há tendência à intenção de compra de marcas próprias, mas não a intenção de comprar esses produtos com frequência.

Os resultados deste estudo podem oferecer contribuições importantes para o marketing de empresas de varejo que adotam ou pretendem adotar as marcas próprias em seu mix de produtos. 0 forte efeito do risco percebido sobre a imagem da marca própria sugere a adoção da estratégia de qualidade garantida nos produtos de marca própria. Ao melhorar aspectos referentes à imagem da loja e ao risco percebido, consequentemente, os gerentes obterão melhoria na imagem da marca própria, na atitude e na intenção de compra desses produtos. Os gerentes podem melhorar a imagem da marca própria por meio de aspectos que influenciam o risco percebido e, ao mesmo tempo, melhorar a imagem da loja para que obtenham melhoria na imagem de suas marcas próprias.

As principais limitações deste estudo relacionam-se com a generalização das descobertas proporcionadas por ele, já que a amostra não foi probabilística. Tal limitação não compromete a contribuição da pesquisa, já que o objetivo foi testar relações entre construtos. O estudo é robusto para população de alta renda, a que mais compra marca própria no Brasil, mas não pode ser generalizado para as classes com menor poder aquisitivo. Sugere-se o desenvolvimento do mesmo estudo aplicando os relacionamentos hipotetizados em uma amostra de consumidores de baixa renda; ou a aplicação em outros setores de mercado que também trabalham com marcas próprias, para testar se os efeitos entre os construtos diferem dos resultados obtidos no contexto de supermercados.

\section{REFERÊNCIAS}

Afthanorhan, W. M. A. B. W. (2013). A comparison of partial least square structural equation modeling (PLS-SEM) and covariance based structural equation modeling (CB-SEM) for confirmatory factor analysis. International Journal of Engineering Science and Innovative Technology, 2(5), 198-205.

Agarwal, S., \& Teas, R. K. (2001). Perceived value: Mediating role of perceived risk. Journal of Marketing Theory \& Practice, 9(4), 1-14. doi:10. 1080/10696679.2001.11501899

Ailawadi, K. L., \& Keller, K. L. (2004). Understanding retail branding: Conceptual insights and research priorities. Journal of Retailing, $80(4), 331-342$. doi:10.1016/j.jretai.2004.10.008

Anderson, J. C., \& Gerbing, D. W. (1988). Structural equation modeling in practice: A review and recommended two-step approach. Psychological Bulletin, 103(3), 411-423. doi:10.1037/0033-2909.103.3.411

Armitage, C. J., \& Conner, M. (2001). Efficacy of the theory of planned behaviour: A meta-analytic review. British Journal of Social Psychology, 40(4), 471-499. doi:10.1348/014466601164939

Associação Brasileira de Supermercados. (2014). Pesquisas sazonais marcas próprias: 19ํestudo da Nielsen aponta oportunidades. Recuperado de http://www.abrasnet.com.br/economia-e-pesquisa/ pesquisas-sazonais/marcas-proprias/

Bao, Y., Bao, Y., \& Sheng, S. (2011). Motivating purchase of private brands: Effects of store image, product signatureness, and quality variation. Journal of Business Research, 64, 220-226. doi:10.1016/j. jbusres.2010.02.007

Beneke, J., Brito, A., \& Garvey, K. A. (2015). Propensity to buy private label merchandise: The contributory effects of store image, price, risk, quality and value in the cognitive stream. International Journal of Retail \& Distribution Management, 43(1), 43-62. doi:10.1108/ ijrdm-09-2013-0175 
Beneke, J., \& Carter, S. (2015). The development of a consumer value proposition of private label brands and the application thereof in a South African retail context. Journal of Retailing and Consumer Services, 25, 22-35. doi:10.1108/ijrdm-09-2013-0175

Beneke, J., \& Zimmerman, N. (2014). Beyond private label panache: The effect of store image and perceived price on brand prestige. Journal of Consumer Marketing, 31(4), 301-311. doi:10.1108/jcm-12-2013-0801

Bido, D. S., Silva, D., Souza, C. A., \& Godoy, A. S. (2010). Mensuração com indicadores formativos nas pesquisas em administração de empresas: Como lidar com a multicolinearidade entre eles? RAEP-Administração: Ensino e Pesquisa, 11(2), 245-269. doi:10.13058/ raep.2010.v11n2.145

Bloemer, J., \& Ruyter, K. (1998). On the relationship between store image, store satisfaction and store loyalty. European Journal of Marketing, 32(5/6), 499. doi:10.1108/03090569810216118

Burton, S., Lichtenstein, D. R., Netemeyer, R. G., \& Garretson, J. A. (1998). A scale for measuring attitude toward private label products and an examination of its psychological and behavioral correlates. Journal of the Academy of Marketing Science, 26(4), 293-306. doi:10.1177/0092070398264003

Chaniotakis, I. E., Lymperopoulos, C., \& Soureli, M. (2010). Consumer's intention of buying own-label premiun food products. Journal of Product \& Brand Management, 19(5), 327-334. doi:10.1108/10610421011068568

Chowdhury, J., Reardon, J., \& Srivastava, R. (1998). Alternative modes of measuring store image: An empirical assessment of structured versus unstructured measures. Journal of Marketing Theory and Practice, 6(2), $72-86$.

Cohen, J. (1988). Statistical power analysis for the behavioral sciences (2nd ed.). New York, EUA: Psychology Press.

Collins-Dodd, C., \& Lindley, T. (2003). Store brands and retail differentiation: The influence of store image and store brand attitude on store own brand perceptions. Journal of Retailing and Consumer Services, 10(6), 345-352. doi:10.1108/10610421011068568

Dawes, J., \& Nenycz-Thiel, M. (2013). Analyzing the intensity of private label competition across retailers. Journal of Business Research, 66(1), 60-66. doi:10.1016/j.jbusres.2011.07.023

Delgado-Ballester, E., Hernandez-Espallardo, M., \& Rodriguez-Orejuela, A. (2014). Store image influences in consumers' perceptions of store brands: The moderating role of value consciousness. European Journal of Marketing, 48(9/10), 1850-1869. doi:10.1108/ejm-02-20120087

Derbaix, C. (1983). Perceived risk and risk believers: An empirical investigation. Journal of Economic Psychology, 3(1), 19-38. doi:10.1016/0167-4870(83)90056-9

Diallo, M. F. (2012). Effects of store image and store brand price-image ons tore brand purchase intention: Application to an emerging market. Journal of Retailing and Consumer Services, 19(3), 360-367. doi:10.1016/j.jretconser.2012.03.010

Dick, A., Jain, A., \& Richardson, P. (1995). Correlates of store brand proneness: Some empirical observations. Journal of Product \& Brand Management, 4(4), 15-22. doi:10.1108/10610429510097663

Dodds, W. B., Monroe, K. B., \& Grewal, D. (1991). Effects of price, brand and store information on buyers' production evaluation. Journal of Marketing Research, 28(3), 307-319. doi:10.2307/3172866

Dolbec, P. Y., \& Chebat, J. C. (2013). The impact of a flagships vs. a brand store on brand attitude, brand attachment and brand equity. Journal of Retailing, 89(4), 460-466. doi:10.1016/j.jretai.2013.06.003
Fishbein, M., \& Ajzen, I. (1975). Belief, attitude, intention, and behavior: An introduction to theory and research. Reading MA: Addison-Wesley.

Fornell, C., \& Larcker, D. F. (1981). Evaluating structural equation models with unobservable variables and measurement error. Journal of Marketing Research, 18(1), 39-50. doi:10.2307/3151312

Golan, E., Roberts, T., \& Ollinger, M. (2004). Savvy buyers spur food safety innovations in meat processing. Amber Waves, 2(2), 22-29.

Grace, D., \& O'Cass, A. (2004). Examining service experiences and post-consumption evaluations. Journal of Services Marketing, 18(6), 450-461. doi:10.1108/08876040410557230

Hair, J., Hult, G. T. M., Ringle, C., \& Sarstedt, M. (2014). A primer on partial least squares structural equation modeling (PLS-SEM). Los Angeles, EUA: SAGE Publications.

Harcar, T., Kara, A., \& Kucukemiroglu, O. (2006). Consumer's perceived value and buying behavior of store brands: An empirical investigation. The Business Review, 5(2), 55-62.

Henseler, J., Ringle, C., \& Sinkovics, R. (2009). The use of partial least squares path modelling in international marketing. In R. R. Sinkovics \& P. N. Ghauri (Eds.), New Challenges to International Marketing (pp.277 - 319). Bingley, Reino Unido: Emerald Group Publishing Limited.

Hidalgo, P., Manssur, E., Olavarrieta, S., \& Farías, P. (2007). Determinantes de la compra de marcas privadas. Revista de Ciências Sociales, 13(2), 205-218.

Hoch, S. J., \& Banerji, S. (1993). When do private labels succeed? Sloan Management Review, 34(4). Recuperado de http://sloanreview.mit. edu/

Hoppe, A., Barcellos, M. D., Vieira, L. M., \& Matos, C. A. (2012). Comportamento do consumidor de produtos orgânicos: Uma aplicação da teoria do comportamento planejado. BASE-Revista de Administração e Contabilidade da Unisinos, 9(2), 174-188.

Hornibrook, S. A., McCarthy, M., \& Fearne, A. (2005). Consumers' perception of risk: The case of beef purchases in Irish supermarkets. International Journal of Retail \& Distribution Management, 33(10), 701715. doi:10.1108/09590550510622263

Huang, Y., \& Huddleston, P. (2009). Retailer premium own-brands: Creating customer loyalty through own-brand products advantage. International Journal of Retail \& Distribution Management, 37(11), 975992. doi:10.1108/09590550910999389

Hyman, M. R., Kopf, D. A., \& Lee, D. (2010). Review of literature - Future research suggestions: Private label brands: Benefits, success factors and future research. Journal of Brand Management, 17(5), 368-389. doi:10.1057/bm.2009.33

Kakkos, N., Trivellas, P., \& Sdrolias, L. (2015). Identifying drivers of purchase intention for private label brands: Preliminary evidence from Greek consumers. Procedia - Social and Behavioral Sciences, 175(12), 522-528. doi:10.1016/j.sbspro.2015.01.1232

Keller, K. L. (1993). Conceptualizing, measuring, and managing customer-based brand equity. Journal of Marketing, 57(1), 1-22. doi: $10.2307 / 1252054$

Knight, D. K., \& Kim, E. Y. (2007). Japanese consumer's need for uniqueness: Effects on brand perceptions and purchase intention. Journal of Fashion Marketing and Management, 11(2), 270-280. doi:10.1108/13612020710751428

Kremer, F., \& Viot, C. (2012). How store brands build retailer brand image. International Journal of Retail \& Distribution Management, 40(7), 528-543. doi:10.1108/09590551211239846 
Laforet, S. (2007). British grocers' brand extension in financial services. Journal of Product \& Brand Management, 16(2), 82-97. doi:10.1108/10610420710739964

Laroche, M., Kim, C., \& Zhou, L. (1996). Brand familiarity and confidence as determinants of purchase intention: An empirical test in a multiple brand context. Journal of Business Research, 27(2), 115-120. doi:10.1016/0148-2963(96)00056-2

Liljander, V., Polsa, P., \& Riel, A. Van. (2009). Modelling consumer responses to an apparel store brand: Store image as a risk reducer. Journal of Retailing and Consumer Services, 16(4), 281-290. 10.1016/j. jretconser.2009.02.005

Martenson, R. (2007). Corporate brand image, satisfaction and store loyalty: A study of the store as a brand, store brands and manufacturer brands. International Journal of Retail \& Distribution Management, 35(7), 544-555. doi:10.1108/09590550710755921

Martineau, P. (1958). The personality of the retail store. Harvard Business Review, 36. Recuperado de https://hbr.org/

Martínez-Ruiz, M. P., Ruiz-Palomino, P., Martinez-Canas, R., \& Blázquez-Resino, J. J. (2014). Consumer satisfaction and loyalty in private-label food stores. British Food Journal, 116(5), 849-871. doi:10.1108/bfj-09-2012-0216

Mieres, C. G., Martín, A. M. D., \& Gutiérrez, J. A. (2006). Antecedents of the difference in perceived risk between store brands and national brands. European Journal of Marketing, 40(1/2), 61-82. doi:10.1108/03090560610637310

Mitchell, V. W. (1998). A role for consumer risk perceptions in grocery retailing. British Food Journal, 100(4), 171-183. doi:10.1108/00070709810207856

Mitra, K., Reiss, M., \& Capella, L. (1999). An examination of perceived: Risk, information search and behavioral intentions in search, experience and credence services. The Journal of Services Marketing, 13(3), 208-228. doi:10.1108/08876049910273763

Nielsen. (2015). Imprensa. Recuperado de http://www.nielsen.com/ $\mathrm{br} / \mathrm{pt} / \mathrm{press}$-room/2015/Em-um-cenario-economico-nao-tao-otimista-marca-propria-se-destaca-por-promocao-aponta-Nielsen.html

Nielsen. (2016). Insights. Recuperado de http://www.nielsen.com/ $\mathrm{br} / \mathrm{pt} /$ insights/news/2016/Marcas-proprias-e-alimentos-saudaveis-sao-duas-das-seis-principais-tendencias-do-varejo-na-America-Latina.html

Olbrich, R., \& Jansen, H. C. (2014). Price-quality relationship in pricing strategies for private labels. Journal of Product \& Brand Management, 23(6), 429-438. doi:10.1108/jpbm-06-2014-0627

Parente, J., \& Barki, E. (2014). Varejo no Brasil: Gestão e estratégia (2a ed.). São Paulo, SP: Atlas.

Pereira, I. (2001). Marcas de supermercado. RAE-Revista de Administração de Empresas, 41(1), 16-27. doi:10.1590/s003475902001000100003

Porral, C. C., \& Lang, M. F. (2015). Private labels: The role of manufacturer identification, brand loyalty and image on purchase intention. British Food Journal, 117(2), 506-522. doi:10.1108/BFJ-06-2014-0216

Porral, C. C., \& Levy-Mangin, J. P. (2016). Food private label brands: The role of consumer trust on loyalty and purchase intention. British Food Journal, 118(3), 679-696. doi:10.1108/bfj-08-2015-0299

Porter, S. S., \& Claycomb, C. (1997). The influence of brand recognition on retail store image. Journal of Product \& Brand Management, 6(6), 373-387. doi:10.1108/10610429710190414
Reardon, J., Miller, C. E., \& Coe, B. (1995). Applied scale development: Measurement of store image. Journal of Applied Business Research, 11(4), 85-93. doi:10.19030/jabr.v11i4.5851

Richardson, A., Dick, S., \& Jain, K. (1994). Extrinsic and intrinsic cue effects on perceptions of store brand quality. The Journal of Marketing, 58(4), 28-36. doi:10.2307/1251914

Richardson, P., Jain, A., \& Dick, A. (1996). Household store brand proneness: A framework. Journal of Retailing, 72(2), 159-185. doi:10.1016/ So022-4359(96)90012-3

Rubio, N., Oubiña, J., \& Villaseñor, N. (2014). Brand awareness-brand quality inference and consumer's risk perception in store brands of food products. Food Quality and Preference, 32, 289-298. doi:10.1016/j.foodqual.2013.09.006

Rzem, H., \& Debabi, M. (2012). Store image as a moderator of store brand attitude. Journal of Business Studies Quarterly, 4(1), 130-148.

Sarkar, S., Sharma, D., \& Kalro, A. D. (2016). Private label brands in an emerging economy: An exploratory study in India. International Journal of Retail \& Distribution Management, 44(2), 203-222. doi:10.1108/ijrdm-07-2015-0102

Semeijn, J., Riel, A. Van, \& Ambrosini, A. (2004). Consumer evaluations of store brands: Effects of store image and product attributes. Journal of Retailing \& Consumer Services, 11(4), 247-258. doi:10.1016/ Sog69-6989(03)00051-1

Sethuraman, R., \& Gielens, K. (2014). Determinants of store brand share. Journal of Retailing, 90 (2), 141-153. doi:10.1016/j.jretai.2014.04.002

Sheau-Fen, Y., Sun-May, L., \& Yu-Ghee, W. (2012). Store brand proneness: Effects of perceived risk, quality and familiarity. Australasian Marketing Journal, 20(1), 48-58. doi:10.1016/j.ausmj.2011.10.014

Shuklay, P., Banerjee, M., \& Adidam, P. T. (2013). The moderating influence of socio-demographic factors on the relationship between consumer psychographics and the attitude towards private label brands. Journal of Consumer Behaviour, 12 (6), 423-435. doi:10.1002/cb.1441

Silva, L. A., Merlo, E. M., \& Nagano, M. S. (2012). Uma análise dos principais elementos influenciadores da tomada de decisão de compra de produtos de marca própria de supermercados. REAd-Revista Eletrônica de Administração, 71(1), 97-129. doi:10.1590/S141323112012000100004

Solomon, M. (2011). O comportamento do consumidor: Comprando, possuindo e sendo (9a ed.). Porto Alegre, RS: Bookman.

Stone, R. N., \& Gronhaug, K. (1993). Perceived risk: Further considerations for marketing discipline. European Journal of Marketing, 27(3), 39-50. doi:10.1108/03090569310026637

Ueltschy, L. C., Krampf, R. F., \& Yannopoulos, P. (2004). A cross national study of perceived consumer risk toward online (internet) purchasing. Multinational Business Review, 12(2), 59-82. doi:10.1108/1525383X200400010

Vahie, A., \& Paswan, A. (2006). Private label brand image: Its relationship with store image and national brand. International Journal of Retail \& Distribution Management, 34(1), 67-84. doi:10.1108/09590550610642828

Wang, E. S. T. (2015). Effect of food service-brand equity on consumer-perceived food value, physical risk, and brand preference. British Food Journal, 117(2), 553-564. doi:10.1108/bfj-09-2013-0260

Wu, P. C. S., Yeh, G. Y. Y., \& Hsiao, C. R. (2011). The effect of store image and service quality on brand image and purchase intention for private label brands. Australasian Marketing Journal, 19(1), 30-39. doi:10.1016/j.ausmj.2010.11.001 
Yeung, R., Yee, W., \& Morris, J. (2010). The effects of risk-reducing strategies on consumer perceived risk and on purchase likelihood: A modelling approach. British Food Journal, 112(3), 306-322. doi:10.1108/00070701011029174
Zielke, S., \& Dobbelstein, T. (2007). Customers' willingness to purchase new store brands. Journal of Product \& Brand Management, 16(2), 112-121. doi:10.1108/10610420710739982 